PROBLEMS

OF EDUCATION

IN THE $21^{\text {st }}$ CENTURY

Volume 51, 2013

${ }^{132}$ ОБРАЗОВАТЕЛЬНАЯ ТЕХНОЛОГИЯ КАК ПСИХОЛОГИЧЕСКАЯ ПРОБЛЕМА

\author{
Валентин Агеев \\ Университет «КАЙНАР», Республика Казахстан \\ Э-почта: ageyev@mail.ru
}

\begin{abstract}
Абстракт
Проблема исследования: противоречие между креативной сущностью исторического человека и когнитивной сущностью социально-культурного человека. В психологическом плане эта проблема представляет собой противоречие между способностью человека как продукта транслирующего образования действовать на основании присвоенньхх норм, образиов и правил, и необходимостью современного сочиума в человеке, способном самостоятельно производить нормы, образцы и правила. В качестве средства разрешения проблемы предлагается новый тип образовательных технологий, основанных не на механизме присвоения, а на механизме порождения.

Значимость исследования заключается в том, что современная социально-историческая ситуаиия в корне отличается от прошльх. Различие заключается в том, что сочиальное развитие в настоямее время резко ускоряется. Становятся необходимыми образовательныле системы, которые обращены не в прошлое (основанные на присвоении и воспроизведении прошлого сочиального опыта), а в будущее. Переориентировка образования возможна только в результате перестройки его с потребления сочиального опыта на его производство.

Методологической основой исследования стал креативный метод. В его основе лежит структура креативного общения, в результате которого учащиеся в проблемной ситуачии генерируют новые значения (знания), которые являются новыми возможностями и выступают в качестве психологических средств конструирования новых способностей.

В качестве основных результатов рассматриваются: воспитание способности к саморазвитию; положительная динамика учебной мотивации и самостоятельности учащихся; системность конструируемых учашимися знаний, их «теоретический» (всеобщий) характер; существенное сокращчение времени образования в результате качественного изменения его результатов.

Ключевые слова: креативное образование, образовательная технология, теория педагогики.

\section{Проблема образовательной технологии как деятельности над деятельностью}

Любая образовательная технология есть деятельность педагога, опосредованная учебной деятельностью учащегося, и представляющая собой способ формирования субъектного опыта учащихся за счет превращения его социальной формы - в индивидуальную. И если предметом учебной деятельности является новая деятельность, то предметом образовательной технологии является сама учебная деятельность. К сожалению, многолетний опыт организации образовательного процесса в разных странах показывает, что далеко не всегда учебная деятельность учащихся является успешной. Среди многих причин этого явления особое значение, на наш взгляд, имеет проблема происхождения новых возможностей.

Если рассматривать образование как фактор, обеспечивающий развитие, а развитие рассматривать как происхождение новых возможностей, то стратегической целью образовательной технологии должно быть создание новых возможностей. Но в действительности современные образовательные технологии проектируются для использования имеющихся возможностей учащихся. Возникновение же новых возможностей либо оста- 
ется «за скобками» (например, в теории оперантного научения Б.Скиннера или в теории социального научения А.Бандуры), либо объясняется социально-детерминированным «созреванием» (культурно-историческая концепция Л.Выготского), «превращением внешней формы уподобляющейся деятельности в ее внутреннюю форму» (А.Леонтьев) или «формированием» по механизму «внешние причины через внутренние условия» (С.Рубинштейн) (натурально-биологическая природа человеческих возможностей в наше время выглядит бесперспективно).

Как видно, все приведенные выше объяснения происхождения новых возможностей основаны на предположении о социальной природе человека и, фактически, утверждают его адаптивную сущность. Этот вывод следует из того, что, с одной стороны, в качестве источника индивидуальных возможностей выступают социальные возможности. А с другой стороны, эти же социальные возможности являются пределами индивидуальных возможностей. Это значит, что, утверждая социальную природу, мы одновременно утверждаем, что индивидуальный человек может развиваться только в пределах актуальной социально-культурной действительности, но не выходить за ее пределы.

При знакомстве с соответствующей психолого-педагогической литературой обращает на себя внимание тот факт, что при описании образовательных технологий, при анализе их действительных или мнимых достоинств авторы, как правило, используя внешнюю атрибутику, оставляя «за скобками» важнейшие вопросы: «Как это возможно?» и «Почему это возможно?». Такой подход характерен практически для всех источников, описывающих образовательные технологии.

Это касается, в первую очередь, педагогического анализа традиционных и инновационных образовательных технологий: Analysis of emerging trends affecting the use of technology in education, 2008; Bhatt, 2002; Carr, 2005; Clyde \& Delohery, 2005; Exploring excellence, 2009-2010; Facer, 2011; National Focus Group on Educational Technology, 2006; Petrina, 2007; Veletsianos, 2010; Борытко, 2006; Брызгалова, 1998; Загвоздкин, 1997; Кларин, 1995; Кларин, 1997; Корсакова, 2011; Краля, 2005; Лукас, 2005; Кукушкина, 2004; Селевко, 2005; Селевко, 1998; Селевко, 2006а; Селевко, 2006b; Бордовская, 2011.

Это касается анализа информационно-коммуникативных технологий, в которых в качестве главного предмета анализа выступают технические средства, а не возможности учащихся и способы их применения в учебной деятельности: Bridgeford \& Selfe, 2004; Haddad, Wadi \& Draxler, 2002; Hirtz \& Dr. Harper, 2008; Information \& Communication Technology, 2010; Information and Communication Technologies in the Teaching and Learning of Foreign Languages, 2004; Information and communication technology in education, 2002; Inspired by Technology, 2010; Johnston \& Barker, 2002; Klopfer, Osterweil, Groff \& Haas, 2009; Loxley \& Julien, 2004; Moursund, 2005; Ollington, 2008; Possony, Pournelle \& Kane, 1997; Soomro, 2010; Voogt \& Knezek, 2008; Красильникова, 2006; Морев, 2004; Муратов, 2004; Федяинова, 2004; Воронкова, 2010.

Не отличаются в этом смысле и современные работы по теории педагогики, образования и образовательных (педагогических) технологий: By Alec Couros For Dr. Cyril Kesten, 2003; Dunne \& Wragg, 2005; Gage, 2009; Grant \& Murray, 2002; Jarvis, 2006; Klein, 2006; Kyriacou, 2009; Learning Theories. 2006; Loughran, 2003; McNamara, 2002; Robertson \& Smith, 2003; Rogers, 2003; Russell \& Munby, 2005; Sharp, Peacock, Johnsey, Simon, Smith, Cross \& Harris, 2009; Westwood, 2008; Woods, 1995; Акулова, Писарева, Пискунова \& Тряпицына, 2005; Аношкина \& Резванов, 2001; Драйден \& Вое, 2003; Иванова, 2002; Новиков, 2006; Новиков, 2008; Новиков, 2005; Новиков, 2000; Сергеев, 2004; Смирнова, 2004; Учитель и ученик, 2002a; Учитель и ученик, 2002b; Якиманская, 1995.

В результате у читателя, пытающегося понять суть какой-либо образовательной технологии, особенно суть технологических новаций, складывается ощущение случайности, произвольности и недостаточной обоснованности предлагаемых технологических усовершенствований.

Наверное, главным при создании образовательной технологии является ответ на 
PROBLEMS

OF EDUCATION

IN THE $21^{\text {st }}$ CENTURY

Volume 51, 2013

134

вопрос, что за существо понимается автором технологии под человеком. Именно из этого понимания следуют параметры самой технологии, необходимость ее создания и предположения о ее возможной эффективности. Но, как правило, авторами технологий и пишущих об образовательных технологиях этот вопрос не обсуждается. Видимо, считается очевидным то, что на самом деле далеко не очевидно.

Важнейшим вопросом является понимание сущности образования. С этой точки зрения практически все авторы исходят из классического понимания образования как способа трансляции и присвоения прошлого социального опыта. На самом деле, это так же неочевидно, как и неочевидна адаптивная сущность человека.

Современная образовательная практика убедительно показывает, что образование как способ формирования человека в соответствии со сложившимся социальнокультурным образом (идеалом) в результате присвоения им социального опыта с точки зрения учащегося представляет собой адаптацию и направлено в прошлое. В результате такого образования даже при активной позиции самого учащегося, выступающего в качестве субъекта учебной деятельности, формируется человек, способный лишь к воспроизводству социального опыта в его индивидуальной форме. При этом, формируется человек, эксплуатирующий свои актуальные возможности, но не способный сделать их предметом своей порождающей деятельности. Такой человек может совершенствоваться в пределах актуальных возможностей, но не способен выйти за их пределы. Не способен качественно изменить собственные возможности, То есть, не способен к саморазвитию

Для успешности образовательной технологии решающее значение имеет психический механизм, который она призвана обеспечить. Этот вопрос в психологопедагогической литературе даже не упоминается. А на самом деле, именно психический механизм определяет и сущность человека как продукта образовательной технологии, и параметры самой образовательной технологии, и возможную эффективность образовательной технологии.

Представляется, что оценка перспективности любой предлагаемой образовательной технологии может быть адекватной только в случае учета выше приведенных параметров. Как правило, при описании образовательной технологии в качестве предмета педагогического анализа выступает структура педагогической (организационноуправленческой) деятельности, детерминируемая структурой образовательной ситуации. В качестве предмета психологического анализа выступает структура совместной учебной деятельности, детерминируемая структурой образовательной ситуации. Но за пределами психолого-педагогического анализа остается вопрос: «Почему учащийся может осуществить учебную деятельность?».

\section{Проблема человека как предмета и продукта образовательной технологии}

По-видимому, проблема образовательной технологии может быть решена только тогда, когда будет решена проблема человека (или предложена внятная модель человека). Можно говорить о том, что в настоящее время в психолого-педагогической науке, в основном, человек понимается как адаптивное существо, в качестве психологического средства адаптации которого выступает сознание, а предметом адаптации является внешняя - естественная, социальная или культурная - среда. С этой точки зрения, все важнейшие базовые категории, которые рассматриваются в современной психологопедагогической науке (развитие, саморазвитие, совершенствование, самопознание, самостоятельность, самоотношение, рефлексия, креативность, творчество и пр. и пр.), представляют собой те или иные аспекты адаптации. Именно адаптивная сущность человека является философско-методологической основой практически всех современных образовательных технологий, но именно она и является самой главной проблемой.

Кроме того, инновации в образовательных технологиях возникают на основании уверенности в том, что учащийся аpriori имеет необходимые возможности действовать в 
соответствии с инновационной образовательной технологией. Эта уверенность базируется на когнитивной (объектной) природе человека, которая, в свою очередь, основывается на молчаливом и очень спорном предположении о том, что новые познавательные возможности возникают в результате осуществления уже имеющихся (С.Рубинштейн). В соответствии с этим предположением, все классические и инновационные образовательные технологии представляют собой способы организации познавательной (когнитивной) деятельности учащихся, а образование понимается как форма присвоения (усвоения) учащимися прошлого социального опыта (в «жестком», «среднем» или «мягком» варианте). В связи с этим, продуктом любой когнитивной технологии становится человек, приобретший старые социальные средства познания и практической деятельности, но живущий в новой исторической ситуации. Здесь важно подчеркнуть, что с точки зрения когнитивной парадигмы, индивидуальный человек не производит новых средств, а присваивает их (при этом не обсуждается проблема, почему учащийся может присвоить, как это возможно). Но такая методологическая установка противоречит всей истории человеческого общества, которая свидетельствует о том, что человек есть существо, самостоятельно производящее средства и организующее собственную ситуацию функционирования и развития.

\section{Психологический анализ возможностей когнитивных (адаптивных) технологий}

Этот анализ должен исходить из базового для когнитивных (адаптивных) технологий субъект-объектного отношения. Именно в рамках этого отношения имеет место познание, включая познание самого себя, и когнитивная (объектная) рефлексия. Методологической основой познавательного (адаптивного) отношения является установка на независимую от субъекта (объектную) природу познаваемой действительности и зависимую от познаваемой действительности (объектную) природу познающего субъекта. В методологическую основу познавательного (адаптивного) отношения также входит установка на социальную (социально-культурную) природу человека (в наше время уже непопулярны плоские идеи дарвинизма о человеке как виде животного, поэтому вряд ли в наше время многочисленны сторонники биологической природы человека). Это значит, что в основе познавательного (адаптивного) отношения к естественному миру лежит как его первооснова познавательное (адаптивное) отношение человека к социальному (социально-культурному) миру.

При этом считается, что человек apriori способен устанавливать адаптивное отношение с социальным миром, а то и просто рождается с такой способностью. Способом реализации (осуществления) этих, пока непонятно как возникающих способностей, как раз и являются когнитивные (адаптивные) образовательные технологии. На наш взгляд, было бы методологической ошибкой считать, что рожденный человек предназначен для адаптации в социум. Тем не менее, опираясь на установку социальной (социальнокультурной) природы индивидуального человека, когнитивные (адаптивные) технологии как раз и обеспечивают индивидуальному человеку такую перспективу. Первичная адаптация в социальный (социально-культурный) мир происходит за счет присвоения прошлого социального опыта (прежних социальных средств). Вторичная адаптация, адаптация в естественный мир, происходит за счет применения присвоенных средств в собственной индивидуальной познавательной и практической деятельности. Таким образом, становится ясным, что миссия человека, сформированного («сформировавшего себя») в условиях когнитивного (адаптивного) отношения, не может быть иной, кроме как воспроизводство актуального социального (социально-культурного) мира. Несмотря на это, одной из распространенных тем, обсуждаемых в психолого-педагогической литературе, является тема творчества (креативности; критического мышления; дивергентного мышления и т.д.). 
PROBLEMS

OF EDUCATION

IN THE $21^{\text {st }}$ CENTURY

Volume 51, 2013

136 понимании образования как способа трансляции, усвоения и воспроизведения прошлого социального опыта. Подобное понимание образования исключает любое творчество как создание нового, ранее не имевшего места. Ссылки на то, что присваиваемый социальный опыт является субъективно новым и для его усвоения необходимо творчество, несостоятельны по той причине, что в основе присвоения (усвоения) лежат механизмы адаптации. То есть приспособления имеющихся возможностей к новой ситуации и новому объекту присвоения. Если же имеющиеся возможности не соответствуют присваиваемому объекту, то присвоения не происходит (что, например, мы имеем в начальной школе, когда до сих пор имеет место неразрешенная проблема усвоения родного языка и математики). Под истинным же творчеством следует понимать способность делать предметом порождения собственные возможности. Тогда при несоответствии актуальных возможностей и новой ситуации предметом порождения становятся сами возможности. В результате созидания новых возможностей (то есть в результате преодоления прежних возможностей) они становятся адекватными новой ситуации. Тем самым, совершится акт саморазвития.

Неразрешимая проблема воспитания творчества в трансляционных (когнитивных; адаптивных) системах образования успешно решается в креативных системах образования. Здесь в качестве средства образования выступает не идеал социального человека, воспроизводящегося и воспроизводящего нормы, эталоны и образцы социальной деятельности, а идеал исторического человека, порождающего новые нормы, эталоны и образцы социальной деятельности. При такой постановке вопроса проблемы образования и творчества совпадают. То есть, проблема образования творческого человека становится проблемой организации креативного образования и адекватных ему образовательных технологий.

При этом, готовность общества к новому (креативному) типу образования не определяется каким-либо конкретным уровнем актуальной креативности его граждан (кроме того, следует иметь в виду несовершенство и субъективность современных психологических методик оценки уровня креативности). А определяется только лишь готовностью общества к самоизменению, его мотивированностью и пониманием необходимости такого самоизменения.

В связи с этим, следует отметить, что в условиях конституирующего в процессе образования человека адаптивного (когнитивного) отношения сама природа творчества выступает как ограниченная. В любом случае, творчество не распространяется на объект, к которому происходит адаптация в результате его познания (естественный, социальный или социально-культурный мир). Творчество так же не распространяется и на собственные когнитивные (адаптивные) возможности человека. Это значит, что творчество есть фактор, обслуживающий адаптацию, основывающийся на актуальных познавательных возможностях, но не способный изменить ни адаптивный характер существования социального (социально-культурного) человека, ни его познавательные возможности.

Субъект-объектное отношение как конституирующее адаптивный тип образования реализуется с помощью множества конкретно-научных методов, но в основе их всех лежат два фундаментальных когнитивных (адаптивных) общенаучных метода: дедуктивный и индуктивный. Поэтому можно утверждать, что в основе всех имеющихся когнитивных образовательных технологий лежит «жестко», «средне» или «мягко» реализуемый, явно или неявно выраженный процесс отражения и присвоения познающим субъектом (учащимся) объективно существующих в социальном пространстве возможностей.

Психологический анализ показывает (Ageyev, 2010) (Агеев, 2011), что дедуктив- 
ный метод адаптации (культурный подход в образовании) осуществляется в два этапа. На первом этапе учащийся присваивает социально-культурные модели и средства их воспроизводства. На втором этапе присвоенные социальные модели становятся мотивами и целями индивидуальной деятельности, с помощью присвоенных средств воспроизводящей социально-культурную действительность. На обоих этапах хорошо просматривается их дедуктивная природа. А именно, первый этап дедуктивно-адаптивного образования («теоретический») осуществляется на основании дедуктивной логики: «от общего (социальные модели) - к единичному (индивидуальные цели)». Второй этап дедуктивно-адаптивного образования («эмпирический») также осуществляется на основании дедуктивной логики: «от общего содержания индивидуальной цели - к единичному содержанию индивидуального эмпирического результата». Поскольку сущностью критерия эффективности любой деятельности является отношение цели и результата, а целью, сформированной на основе дедуктивного метода индивидуальной деятельности, является присвоенная социально-культурная модель, постольку такая индивидуальная деятельность по своей природе является способом практического воспроизводства социально-культурных моделей. В этом и заключается ее социально-культурный смысл.

Первый этап осуществляется за счет обеспечения «прямого» механизма знакового опосредования (то есть, распредмечивания объективной социально-культурной действительности с помощью субъективных значений слов как психологических средств). Этот механизм обеспечивает базовый процесс интериоризации, под которым понимается трансформация систем социально-культурных (внешних) моделей в системы психических (внутренних) целей. Эти трансформации происходят с помощью культурных знаков как социальных средств, объективные (социальные) значения которых трансформируются в субъективные (индивидуальные) значения. Субъективные значения становятся психологическими средствами организации учащимся собственной индивидуальной деятельности (поведения), что является свидетельством рефлексивной природы деятельности (поведения).

В какой степени субъективные (индивидуальные) значения являются адекватными объективным (социально-культурным) значениям, в такой степени рефлексивная деятельность (поведение) имеет социально-культурный смысл. Но механизм «прямого» знакового опосредования «работает» в определенных психологических границах и не способен преодолеть социально-культурный предел. В качестве психологической границы механизма знакового опосредования выступает возможность индивидуального человека осуществить интериоризацию (в соответствии с концепцией порогов распредмечивания Г.С.Батищева (Батищев, 1997)). А в качестве социально-культурного предела механизма «прямого» знакового опосредования выступает объективная идеальная форма (объективное значение), Из этого следует, что механизм «прямого» знакового опосредования «работает» только в психологических границах и никогда не выходит за социальный предел.

Второй этап осуществляется за счет механизма «обратного» знакового опосредования (переобозначения объективной социально-культурной действительности с помощью субъективных значений слов как психологических средств). Этот механизм обеспечивает базовый процесс экстериоризации, под которым понимается предметная деятельность как практическое конструирование социально-культурной (внешней) действительности в соответствии с системами индивидуальных (внутренних) целей. Это конструирование происходит с помощью субъективных знаков как индивидуальных средств, субъективные (индивидуальные) значения которых трансформируются в объективные (социальные) значения. Объективные значения становятся социальными средствами организации совместной деятельности, что является свидетельством рефлексивной природы совместной деятельности. 
PROBLEMS

OF EDUCATION

IN THE $21^{\text {st }}$ CENTURY

Volume 51,2013

138

В какой степени объективные (социально-культурные) значения адекватны субъективным (индивидуальным) значениям, в такой степени индивидуальная предметная деятельность имеет социально-культурный смысл. Но механизм «обратного» знакового опосредования также «работает» в определенных психологических границах и не способен преодолеть социальный предел. В качестве психологической границы механизма «обратного» знакового опосредования выступает субъективная идеальная форма, а в качестве социального предела выступает объективная идеальная форма как источник субъективной идеальной формы, Механизм «обратного» знакового опосредования обеспечивает экстериоризацию (предметную деятельность) в психологических границах и никогда не выводит человека за социальный предел.

Психологический анализ показывает (Ageyev, 2010) (Агеев, 2011), что индуктивный метод адаптации (социальный подход к образованию) также осуществляется в два этапа. На первом этапе у учащегося формируется модель объективной реальности социальных взаимодействий (субъективная реальность идеальной формы) и присваиваются средства ее воспроизводства. На втором этапе внешние социальные причины превращаются в мотивы и цели индивидуальной (рефлекторной) деятельности, с помощью присвоенных средств воспроизводящей действительность социальных взаимодействий только в том случае, если они адекватны внутренней субъективной реальности идеальной формы (субъективному опыту). На обоих этапах хорошо просматривается их индуктивная природа. А именно, первый этап индуктивно-адаптивного образования («теоретический») осуществляется на основании индуктивной логики: «от единичного (единичные воздействия внешних социальных причин) - к общему (субъективная реальность как модель системы социальных взаимодействий)». Второй этап индуктивно-адаптивного образования («эмпирический») также осуществляется на основании индуктивной логики: «от единичной реальности индивидуальной цели - к общей реальности системы социальных результатов». Поскольку критерием эффективности всякой деятельности является соотношение цели и результата, постольку индивидуальная рефлекторная деятельность по своей природе является воспроизводящей реальность социальных взаимодействий. В этом и заключается ее социальный смысл.

Первый этап осуществляется за счет механизма «прямого» причинного опосредования (отражение социальной реальности с помощью рефлекторной деятельности мозга с помощью социальных причин как средств отражения). Этот механизм обеспечивает базовый процесс формирования субъективного опыта, под которым понимается трансформация объективной реальности системы внешних социальных взаимодействий в субъективную реальность идеальной формы в результате осуществления отражения (познания). Эти трансформации происходят с помощью причин как социальных средств, объективная (социальная) реальность которых трансформируются в субъективную (индивидуальную) реальность. Под воздействием социальных причин, субъективная реальность становится психологическим фактором детерминации индивидуальной деятельности, что является свидетельством ее рефлекторной природы.

В какой степени субъективная (индивидуальная) реальность является адекватной объективной (социальной) реальности, в той степени рефлекторная деятельность имеет социальный смысл. Но механизм «прямого» причинного опосредования «работает» в определенных психологических границах и не способен преодолеть социальный предел. В качестве психологической границы «прямого» причинного опосредования выступает субъективная реальность, представляющая собой индивидуальную проекции социальной реальности. А в качестве социального предела «прямого» причинного опосредования выступает объективная реальность социальных взаимодействий, Из этого следует, что механизм «прямого» причинного опосредования обеспечивает отражение в психологических границах и никогда не выходит за социальный предел. 
Второй этап осуществляется за счет механизма «обратного» причинного опосредования (переформирования объективной системы социальных взаимодействий с помощью субъективной реальности как психологического средства). Этот механизм обеспечивает ответное рефлекторное действие, которое представляет собой практическое воздействие человека на объективную реальность социальных взаимодействий в соответствии с субъективной реальностью индивидуальных (внутренних) целей. Это воздействие происходит с помощью средств, превращающих субъективную реальность целей в объективную реальность социальных результатов. Объективная реальность индивидуальных результатов становится системой средств организации социальных взаимодействий, что является свидетельством рефлекторной природы социальных взаимодействий.

В той степени, в которой объективная реальность социальных результатов является адекватной объективной реальности индивидуальных результатов, в той степени индивидуальная рефлекторная деятельность имеет социальный смысл. Но механизм «обратного» причинного опосредования также «работает» в определенных психологических границах и также не способен преодолеть социальный предел. В качестве психологической границы механизма «обратного» причинного опосредования выступает субъективная реальность как возможность индивидуального человека осуществить рефлекторное действие, представляющая собой проекцию объективной социальной реальности. А в качестве социального предела механизма «обратного» причинного опосредования выступает объективная реальность как источник возможности рефлекторного действия, Из этого следует, что механизм «обратного» причинного опосредования «работает» в психологических границах и никогда не выводит человека за социальный предел.

\section{Проблема метода организации креативной образовательной ситуации}

Из проведенного психологического анализа можно сделать следующий вывод. Когнитивный (адаптивный) метод организации образовательной ситуации (в обоих его вариантах - дедуктивном и индуктивном) является ограниченным социальной практикой (социально-культурным опытом) и не может быть применим к организации креативного образования. В условиях учебно-познавательной ситуации, за счет организации учебнопознавательной деятельности невозможно воспитать способность преодолевать внешние (социальные) и внутренние (психологические) границы. Нужен метод, предметом которого станут не возможности действовать в пределах и границах, а сами пределы и границы возможности действовать. Идея такого метода не может быть выведена из объективной (объектной) природы естественного, социального или культурного предметного мира, поскольку именно объектность является порождающей основой всех пределов и границ индивидуального человека. Для формулирования необходимого метода следует природу (предметный мир) понять как субъекта собственного существования (субъекта собственных изменений). При этом, субъектность следует понимать как способность природы (предметного мира) быть детерминантой собственных изменений (основанием собственных изменений).

Индуктивный и дедуктивный методы организации познавательной (учебнопознавательной) деятельности, по сути, представляют собой методы эмпирической верификации априорного знания. В случае индуктивного метода в качестве источника такого априорного знания рассматривается объективная (социальная) реальность, результатом отражения которой становится субъективная (индивидуальная) реальность как психологическое средство познания. В случае дедуктивного метода в качестве источника априорного знания рассматривается культура (объективная идеальная форма) как действительность социального опыта, результатом присвоения которой становится индивидуальный опыт (субъективная идеальная форма) как психологическое средство познания,

И в том, и в другом случаях носителем и источником априорного знания является 
PROBLEMS

OF EDUCATION

IN THE $21^{\text {st }}$ CENTURY

Volume 51,2013

140 ется его реальная форма, а предметом дедуктивного метода - его идеальная форма. Но в любом случае, формируемая объектным образом субъективность (субъектность) есть социально-культурная проекция, формирующая индивидуального человека и транслирующая ему его собственные мотивационные факторы. С этой точки зрения, социум и культура выступают в качестве внешних пределов человеческой индивидуальности, а субъективность (субъектность), которая в этом случае имеет объектную природу и представляет собой проекцию социума на индивида, выступает в качестве ее внутреннего предела.

Поэтому для конструирования нужного метода не подходит ни актуальный социум, ни актуальная культура, а необходим новый источник. И таким источником является история как последовательная смена типов социальности и индивидуальности. Если социальность (конкретно-исторический социум) рассматривается в отрыве от собственной истории происхождения, то тогда конкретно-исторический социум для индивидуального человека выступает объективно, только как объект его познания (познавательной деятельности). Но если социум рассматривается в процессе своего происхождения как результат собственной истории, а в качестве движущей силы истории рассматривается индивидуальный человек (совместная деятельность индивидуальных людей), то тогда социум представляет собой субъект, субъектные силы которого персонифицированы в индивидуальном человеке. И тогда социум для индивидуального человека выступает субъективно (субъектно), как предмет его порождающей (креативной) деятельности. Социальная субъектность осуществляется через субъектность индивидуального человека в результате порождения его собственной истории как индивидуальной формы социальной истории. Метод организации порождения человеком собственной истории есть креативный (креативно-исторический) метод. Положенный в основу образовательной системы, креативный метод дает возможность конструирования системы креативного образования.

Метод. Исходя из сформулированных выше положений следует, что методом организации креативной образовательной практики, положенным в основу креативных образовательных технологий, не может быть когнитивный (адаптивный) метод. Познание как субъект-объектное отношение всегда предполагает подчиненность субъекта познания познаваемому объекту и, тем самым, ограниченность познающего субъекта познаваемым объектом. В условиях познавательного (субъект-объектного) отношения субъект познания никогда не выступает в качестве созидателя познаваемого объекта. Наоборот, его цель состоит в том, чтобы в результате познания обнаружить (открыть; сформулировать) существующие независимо от него законы существования познаваемого объекта с тем, чтобы самому начать существовать на основании этих законом. В противном случае, в случае неадекватности законов существования субъекта и законов существования объекта субъект теряет все возможности своего существования. Потому что возможности своего существования субъект черпает (заимствует; присваивает) у познаваемого объекта (это в равной степени относится и к индуктивному, и дедуктивному методам познания).

Методологической основой когнитивного метода является наблюдение, которое представляет собой преднамеренное (целесообразное) отношение субъекта к познаваемому объекту. При этом цель есть не что иное, как исходное априорное знание, которое в процессе познавательной деятельности соотносится с эмпирическими результатами познавательной деятельности. Тем самым, когнитивный метод (и наблюдение как его исходная форма) не является методом возникновения нового знания (нового социального опыта), о чем в свое время говорил еще Карл Поппер (Поппер, 2002, с.67). Проблемой когнитивного метода является проблема происхождения априорного знания, но в психолого-педагогической литературе она практически не обсуждается. Точнее, указывается на социум как источник априорного для индивидуального человека знания, подчеркивая тем самым в высшей степени спорный тезис о социальной природе индивидуального человека. 
Когнитивный метод выражает объектную природу человека как субъекта. В этом случае в качестве источника внутреннего (субъектного) мира выступает внешний (объектный) мир (это утверждал в свое время еще Сократ (Ярошевский, 1996)). Одновременно с этим, когнитивная парадигма утверждает адаптивную природу человека, поскольку смысл когнитивного человека состоит в превращении законов существования объекта в законы своего индивидуального существования. Т.е. в адаптации. При этом, не имеет значения адаптация в какую среду происходит: естественную, социальную или культурную.

Для конструирования нового метода необходимо отказаться от положений когнитивной парадигмы и, в первую очередь, от объектной (социальной; социально-культурной; культурной) природы человека. Необходимо смоделировать субъектный мир, мир, который не порождает человека, а сам порождается им и становится условием самопорождения человека. На наш взгляд, человек - не порождение природы, не ее продукт, а персонифицированная внутренняя сила самой природы, ее потенция и ее способность к самопроизводству и саморазвитию. Та сила, которая производит самое природу, является источником ее саморазвития. И если объектный мир - это мир, сущность которого независима от человека, его сознания и деятельности, то субъектный мир - это мир и его сущность как продукт человеческой деятельности, обусловленный его сознанием. Метод, который выражает субъектную природу человека, источником происхождения которого является он сам, есть креативный (креативно-исторический) метод.

\section{Возможные пути решения проблемы образовательных технологий}

Некоторые идеи возможного решения проблемы. Образовательная практика, качество которой никак не удается изменить никакими технологическими ухищрениями, является свидетельством существенной фундаментальности проблем, с какими столкнулось человечество. Решение этих проблем требует такой же фундаментальности, адекватной самим проблемам.

Первым предположением на пути поиска решений является предположение о том, что человек не является адаптивным существом. По крайней мере, адаптивность не раскрывает его сущностной природы, не является его сущностью. Это предположение основывается на исторических фактах, которые свидетельствуют в пользу креативной сущности человека. Вся история человечества свидетельствует о том, что именно человек своими руками творил себя, свой социум, свою культуру и собственную историю. Прекрасным образчиком веры в такого человека навсегда останется «Речь о достоинстве человека» Джованни Пико делла Мирандолы (Реале \& Антисери, 1995, с.271), которую ему, к сожалению, так и не удалость произнести.

Вторым предположением является предположение о том, что образование не является потребителем прошлого социального опыта и прошлого образа человека, но представляет собой способ и ситуацию порождения нового социального опыта новым человеком, возникающим в процессе созидания нового социального опыта. Это положение представляется достаточно очевидным, поскольку будущее не есть перенесенное в будущее прошлое. Но в ситуации присвоения новыми поколениями прошлого социального опыта дело обстоит именно так - социальное прошлое переносится в индивидуальное будущее.

Третьим предположением является предположение о том, что существенным в поиске решения проблем является психический механизм образования, который должен быть обеспечен соответствующей образовательной технологией. Понятно, что базовым процессов креативного образования не может быть присвоение (усвоение), обеспечиваемое интериоризацией. Поэтому искомый механизм не может быть знаковым опосредованием, характерным для социально-культурных концепций образовательного процесса, поскольку в его основе лежит присвоение объективной идеальной формы культуры и 
PROBLEMS

OF EDUCATION

IN THE $21^{\text {st }}$ CENTURY

Volume 51, 2013

142

мощью культурного знака как средства. Искомый механизм не может быть причинным опосредованием, характерным для социально-рефлекторных концепций образования, поскольку в его основе лежит присвоение объективной реальной формы причины и превращение ее в цель индивидуальной деятельности с помощью субъективной идеальной формы как средства.

Четвертым предположением является предположение о том, что базовым процессом, конституирующим искомое образование, является саморазвитие. Причем, под саморазвитием следует понимать не процесс самоизменения, детерминированный генетическими факторами, не процесс количественных изменений в результате самостоятельного применения присвоенных средств, а процесс самостоятельного создания средств и качественного изменения себя с помощью этих созданных средств.

Пятым предположением является предположение о том, что механизмом, обеспечивающим креативный образовательный процесс, может быть только механизм креативного опосредования. В его основе лежит структура субъект-субъектного отношения. При этом, субъект-субъектное отношение в своей исходной форме понимается как отношение себя прошлого - к себе будущему. Такое отношение может возникнуть только в условиях особой проблемы, когда прошлые актуальные возможности перестают соответствовать новым предметным условиям. Решением такой проблемы (проблемы развития) является конструирование новых возможностей, адекватных новым предметным условиям, а форма, в условиях которых становится возможным такое конструирование, есть креативное общение (креативный диалог). С учетом того, что в качестве возможностей человеческой деятельности выступают ее идеальные формы (цели и способы), которые являются психологическим содержанием значений, креативное общение есть форма порождения (производства) новых значений как новых возможностей индивидуального человека. Такое производство вполне осуществимо потому, что в условиях креативного общения возникает креативная рефлексия как порождающая новые значения деятельность, в качестве средства которой выступает объектная историческая логика, трансформируемая человеком в его собственную субъектную логику. Возникнув в результате исторической рефлексии, субъектная логика развития становится в новых предметных условиях психологическим средством порождения новых значений. В свою очередь, новые значения становятся средством конструирования деятельности нового качества, т.е. саморазвития.

Исходя из перечисленных предположений, основываясь на креативно-историческом методе и механизме креативного опосредования, была разработана образовательная технология конструирования новых возможностей, которая была апробирована в течение многих лет в условиях экспериментальной образовательной практики.

\section{Технология конструирования новых возможностей как пример решения проблемы образовательных технологий}

Креативное образование и креативная образовательная ситуация. Воспитание креативного человека как исторического субъекта осуществляется на основании иной, не когнитивной схемы. Основой новой схемы является понимание образования не как ситуации трансляции/присвоения/освоения прошлого социального опыта, а как ситуации порождения человеком самого себя в условиях необходимости порождения нового социального опыта. При этом, новый социальный опыт возникает первоначально в индивидуальной (а точнее, в междусубъектной форме (Батищев, 1997) (Рубинштейн, 2003)). И только затем, по мере распространения его в социальном пространстве, он превращается из индивидуальной (междусубъектной) формы - в социальную форму. Сущностью креативного образования является воспитание способности к саморазвитию, одним из главных компонентов которой является способность создавать новые психологические (идеальные) и реальные средства собственного изменения. 
Креативная схема представляет собой схему особого типа общения (креативного диалога (Батищев, 1997) (Рубинштейн, 2003) (Бахтин, 2000) (Бубер, 1999)), в результате которого реконструируется прошлая субъектная история, которая в новых условиях превращается в будущую субъектную историю. Поскольку такая реконструкция и трансформация субъектной истории возможна только в условиях поиска решения объективной исторической проблемы, то объективным основанием для реконструкции прошлой субъектной истории становится прошлая объектная (социально-культурная) история. При этом, будущая объектная история возникает в субъектной форме, которая выступает в качестве средства порождения будущей объективной истории. Тем самым, субъективность (субъектность) выступает в качестве формы развития объективности (объектности).

Такие возможности человек черпает в социальной истории и в истории собственной субъектности. А креативное общение (креативный диалог) есть форма порождения новых возможностей человека, которые затем трансформируются в новые социальные возможности.

Образовательная технология конструирования новых возможностей. Одним из возможных практических способов реализации креативного образования является технология конструирования новых возможностей (Агеев, 2003a) (Агеев, 2003b) (Агеев, 2004a) (Агеев, 2004b). Эта технология (а скорее, тип технологий) отличается от имеющихся современных образовательных технологий тем, что является деятельностью, предметом которой является деятельность создания самими учащимися своих новых возможностей. Если когнитивные (адаптивные) технологии исходят из актуального (наличного) состояния возможностей, то креативные технологии делают возможности образующегося человека предметом созидания. ностей

Основные принцииы реализации технологии конструирования новых возмож-

Порождающая новые возможности деятельность сама выступает предметом конструирования учащимися, исходя из структуры проблемной ситуации. Целью конструирующей деятельности является создание психологической структуры предметной деятельности нового качества. Основными принципами организации конструирующей деятельности являются следующие: принциип самостоятельности (от формулировании целей до практической их реализации), принциип общзего решения, принции общей ответственности, принциип общих критериев, принции равньх возможностей, принцип pавных прав (суверенность и право учащегося поступать так, как он считает нужным), принции действия за пределами актуальных возможностей (устремленность к непрерывному преодолению внешних и внутренних границ), принциип личной заинтересованности (стремление к саморазвитию), принцип личностного знания (знание и значение в равной степени является продуктом и совместной, и индивидуальной деятельностей), принцип соблюдения права меньшинства (право каждого учащегося на собственную точку зрения). стей

Основные формы реализации технологии конструирования новых возможно-

Эти принципы, лежащие в основе технологии конструирования новых возможностей, реализуются в системе следующих организационных форм: конструктивная дискуссия (креативный диалог) (организуется на ключевых этапах создания согласованных схем, критериев и средств осуществления), самостоятельное формулирование проблемы, самостоятельное формулирование гипотез, самостоятельное формулирование ичелей, самостоятельное формулирование задач, самостоятельное конструирование критериев самоконтроля и самооценки, самостоятельное конструирование способов практического действия, самостоятельное конструирование средств практического действия, взаимный контроль, самоконтроль, взаимная оиенка, самооченка, самоанализ, самостоятельная практическая работа, самостоятельное проектирование общего результата решения, самостоятельное обоснование собственной версии предполагаемого результата решения, самостоятельные выводы. 
PROBLEMS

OF EDUCATION

IN THE $21^{\text {st }}$ CENTURY

Volume 51,2013

144

Таким образом, в результате креативного образования воспитывается способность достраивать и перестраивать психологическую структуру собственной деятельности, приводя ее в соответствие с качественно новой реальностью. Человек, воспитанный в условиях креативного образования, становится способным к саморазвитию за счет того, что он рефлексирует внутреннюю логику развития социально-культурного и реального миров, становится способным прогнозировать и предвидеть их развитие и, в соответствии с прогнозируемым развитием этих миров, прогнозировать и практически осуществлять собственное развитие. На практике способность к саморазвитию становится способностью решать нестандартные проблемы в нестандартных ситуациях. Способность решать проблемы собственного развития становится главной способностью креативного человека.

\section{Обобщение}

Проблемы современного образования, наиболее ярко проявляющиеся в сфере образовательных технологий, на самом деле, являются отражением масштабных проблем современного социума. Современный человек все более остро ощущает пропасть между собой и обществом, между собой и социумом. Современный социум представляется некоей отчужденной действительностью, вынуждающей и принуждающей человека жить по его часто чуждым для индивидуального человека законам. Наступившая информационная эпоха, информационное общество только обостряют это отчуждение, поскольку источником информации выступает социум, а индивидуальный человек выступает в качестве пассивного (или активного) потребителя этой информации.

В результате такого положения дел все больший акцент делается на когнитивных (адаптивных) способностях человека, и совершенно исключается востребованность его креативных (порождающих) способностей. На практике это приводит к тому, что в нестандартных ситуациях, когда социум как главный источник информации перестает быть эффективным, человек остается один на один с проблемой и эта ситуация для него оказывается безвыходной. Иллюстрацией к этому может служить резкое увеличение в наше сложное время психических заболеваний, суицидов, невротизации населения, в особенности, школьников и пр. и пр.

В масштабах социума это приводит к обострению экологических, экономических, финансовых, социальных, этнических и пр. проблем, возникающих в результате социальной стагнации и невозможности предсказать собственное развитие даже на ближайшую перспективу. В масштабе индивидуального человека это приводит к потере смысла жизни, бездуховности, агрессивности, психическим заболеваниям в результате невостребованности креативных способностей, невозможности своей индивидуальной деятельностью непосредственно влиять на социальную ситуацию.

Один из вариантов решения проблемы видится в переориентировке общества с режима функционирования на режим качественного самообновления за счет предоставления возможности «выхода» креативным способностям каждого человека. Не человек должен рассматриваться в качестве продукта социума, а социум, общество и сам человек должен стать продуктом креативной деятельности. В этом случае будет восстановлена историческая справедливость, поскольку единственным источником самообновления социума являются взаимодействующие люди, а не наоборот.

Кажущаяся на первый взгляд практическая невозможность переключения на новый социальный режим, опасения за неподготовленность общества, беспокойство о необходимости дополнительных специальных мер и времени и пр. является плодом репродуктивного мышления и является скорее социально-политической, а не психологопедагогической проблемой. Из психологии образования известно, что любой ребенок изначально готов принять и успешно осуществлять любой подход, и когнитивный (адаптивный), и креативный (порождающий). Если начать «двигать» социальную ситуацию, 
воспитывая учащихся на основе новых принципов, то через некоторое время в социуме накопится «критическая масса» людей, которые и перестроят социальную ситуацию в

целом. В этом случае система образования выполнит свою важнейшую, на наш взгляд, функцию опережающего развития и действительно станет источником развития всего социума.

\section{References}

Ageyev, V. (2010). Creative education as a way of the organization of self-development. Manuscript. LAP Lambert Academic Publishing. Germany, Saarbrucken.

Analysis of emerging trends affecting the use of technology in education (2008). Research report. University of Oxford (Department of Education), Nottingham University (Learning Sciences Research Institute, LSRI), Sero consulting, Kable (part of the Guardian media group) and Oakleigh Consulting Ltd, for Becta. http://www.becta.org.uk

Bhatt, B. D. (2002) Modern methods of teaching. Concept and Techniques. Kanishka publishers, distributors, New Delhi, India.

Bridgeford, T., Kitalong, Karla Saari, \& Selfe, D. (2004). Innovative approaches to teaching technical communication. Utah State University Press, Logan, Utah, USA.

By Alec Couros For Dr. Cyril Kesten (2003). Innovation, Change Theory and the Acceptance of New Technologies: A Literature Review. November.

Carr, W. (2005). Quality in teaching: arguments for a reflective profession. Taylor \& Francis e-Library, London, New York and Philadelphia.

Clyde, W., \& Delohery, A. (2005). Using Technology in Teaching. Yale University Press, New Haven \& London.

Dunne, R., \& Wragg, T. (2005). Effective teaching. Taylor \& Francis e-Library, London \& New York.

Exploring excellence (2009-2010). International Society for Technology in Education. Annual Report. www.iste.org

Facer, K. (2011). Learning Futures. Education, technology and social change. London \& New York, Taylor \& Francis e-Library.

Gage, N. L. (2009) A Conception of Teaching. Springer Science + Business Media, New York, USA.

Grant, G., \& Murray, C. E. (2002) Teaching in America: the slow revolution. Harvard University Press Cambridge, Massachusetts, London, England.

Haddad, W. D., \& Draxler, A. (2002). Technologies for education: Potentials, Parameters, and Prospects. UNESCO by Knowledge Enterprise, Inc. Paris, France \& Washington, USA.

Hirtz, S., \& Harper, D. G. (2008) Education for a Digital World. Advice, guidelines, and effective practice from around the globe. BC campus and Commonwealth of Learning, Vancouver, British Columbia, Canada. www.bccampus.ca

Information \& Communication Technology (2010). Standard VIII. Government of Kerala Department of General Education. Prepared by IT@School Project For State Council for Education Research and Training (SCERT), Kerala, India. www.itschool.gov.in

Information and Communication Technologies in the Teaching and Learning of Foreign Languages: State-of-the-Art, Needs and Perspectives (2004). Analytical Survey. UNESCO Institute for Information Technologies in Education, Moscow.

Information and communication technology in education (2002). A curriculum for schools and programme of teacher development. Division of Higher Education, UNESCO, Paris, France.

Inspired by Technology, Driven by Pedagogy (2010). A systemic approach to technology-based school innovations. Centre for Educational Research and Innovation OECD, Paris, France.www.oecd. org/publishing/corrigendawww.sourceoecd.org/education/ 9789264094789

Jarvis, P. (2006). The theory and practice of teaching. Second edition. Taylor \& Francis e-Library, London-New York.

Johnston, J., \& Barker, L. T. (2002). Assessing the Impact of Technology in Teaching and Learning. A Sourcebook for Evaluators. Published by Institute for Social Research, University of Michigan, USA.

Klein, M. B. (2006). New teaching and teacher issues. Nova Science Publishers, Inc., New York, USA.

Klopfer, Eric; Osterweil, Scot; Groff, Jennifer \& Haas, Jason (2009). Using the technology of today, in the classroom today. The Instructional Power of digital games, social networking, simulations and how teachers can leverage them. Massachusetts Institute of Technology, USA. 
PROBLEMS

OF EDUCATION

IN THE $21^{\text {st }}$ CENTURY Volume 51, 2013

146 Kyriacou, C. (2009). Effective Teaching in Schools. Theory and Practice. Third Edition. Nelson Thornes Ltd, London, United Kingdom.

Learning Theories (2006). From Wikibooks, the open-content textbooks collection. http://en.wikibooks. org/wiki/Learning_Theories

Loughran, J. (2003). Researching Teaching: Methodologies and Practices for Understanding Pedagogy. Taylor \& Francis e-Library, London \& Philadelphia.

Loxley, W., \& Julien, P. (2004). Information and Communication Technologies in Education and Training in Asia and the Pacific. Asian Development Bank. http://www.adb.org/Education McNamara, D. (2002). Classroom pedagogy and primary practice. London \& New York.

Moursund, D. (2005). Introduction to Information and Communication Technology in Education. University of Oregon, Eugene, Oregon, USA.

National Focus Group on Educational Technology (2005). Publication Department by the Secretary, National Council of Educational Research and Training, Sri Aurobindo Marg, New Delhi.

Ollington, G. F. (2008) Teachers \& teaching: strategies, innovations and problem solving. Nova Science Publishers, Inc., New York, USA.

Petrina, S. (2007). Advanced Teaching Methods for the Technology Classroom. The University of British Columbia, Canada.

Possony, S. T., Pournelle, J. E., \& Kane, F. X. (1997). The strategy of technology. Electronic Edition, prepared by WebWrights. Studio City, California, USA.

Robertson, A., \& Smith, B. (2003). Teaching in the 21st century: adapting writing pedagogies to the curriculum. Published in the Taylor \& Francis e-Library, New York, USA.

Rogers, B. (2003). Effective Supply Teaching. Behaviour Management, Classroom Discipline and Colleague Support. Paul Chapman Publishing, London, England.

Russell, T., \& Munby, H. (2005). Teachers and teaching: from classroom to reflection. Taylor \& Francis e-Library, London, New York, Philadelphia.

Sharp, J., Peacock, G., Johnsey, R., Simon, S., Smith, R., Cross, A., \& Harris, D. (2009). Primary Science. Teaching Theory and Practice. Fourth edition. Published by Learning Matters Ltd., Exeter, Great Britain.

Soomro, S. (2010). New Achievements in Technology, Education and Development. Published by In-The, Vukovar, Croatia, India.

Veletsianos, G. (Editor) (2010). Emerging Technologies in Distance Education. AU Press, Athabasca University, Edmonton, Canada.

Voogt, J., \& Knezek, G. (2008). International Handbook of Information Technology in Primary and Secondary Education. Springer Science+Business Media, LLC, New York, USA.

Westwood, P. S. (2008) What teachers need to know about teaching methods. ACER Press, Camberwell Victoria, Australia.

Woods, P. (1995). Creative teachers in primary schools. Open University Press, Buckingham \& Philadelphia.

Агеев, В. В. (2010) Психолого-педагогические основы саморазвития человека. Издательство университета «Кайнар», Алматы, Казахстан.

Агеев, В. В. (2003а). Технология конструирования новых возможностей. Открытая школа. Информациионно-методический журнал. Алматы, Казахстан, №11 (24), с.12-16.

Агеев, В. В. (2003b). Технология конструирования новых возможностей. Oткрытая школа. Информационно-методический журнал. Алматы, Казахстан, №12 (25), с.32-37.

Агеев, В. В. (2004a). Технология конструирования новых возможностей. Открытая школа. Информационно-методический журнал. Алматы, Казахстан, №1 (26), с.5-8.

Агеев, В. В. (2004b). Технология конструирования новых возможностей. Открытая школа. Информационно-методический журнал. Алматы, Казахстан, №2 (27), с.33-37.

Акулова, О. В; Писарева, С. А; Пискунова, Е. В., \& Тряпицына, А. П. (2005). Современная школа: onыт модернизации: Книга для учителя / Под общ. ред. А. П.Тряпицыной.. Изд-во РГПУ им. А. И. Герцена, Санкт-Петербург, Россия.

Аношкина, В. Л., \& Резванов, С. В. (2001). Образование. Инновация. Будущее (Методологические и социокультурные проблемь). Изд-во РО ИПК и ПРО, Ростов-на-Дону, Россия.

Батищев, Г. С. (1997). Введение в диалектику творчества. Изд-во РХГИ, Санкт-Петербург, Россия.

Бахтин, М. М. (2000). Автор и герой: к философским проблемам гуманитарных наук. Азбука, Россия. 
Борытко, Н. М. (2006). Педагогические технологии: Учебник для студентов педагогических вузов / Н. М. Борытко, И. А. Соловцова, А. М. Байбаков. Под ред. Н. М.Борытко. Изд-во ВГИПК РО, Волгоград, Россия.

Брызгалова, С. И. (1998). Проблемное обучение в начальной школе: Учеб. пособие. Изд. 2-е, испр. и доп. / Калинингр. ун-т. Калининград, Россия. Бубер, М. (1999). Два образа веры. Издательский дом АСТ, Москва, Россия.

Воронкова, О. Б. (2010). Информационные технологии в образовании: интерактивные методы / О.Б.Воронкова. Феникс, Ростов-на-Дону, Россия.

Драйден, Гордон, \& Вое, Джаннетт (2003). Революиия в обучении. Научить мир учиться по-новому. Парвинэ, Москва, Россия.

Реале, Дж, \& Антисери, Д. (1995). Западная философия от истоков до наших дней. Том 2. Средневековье. ТОО ТК «Петрополис», Санкт-Петербург, Россия. Загвоздкин, В. К. (1997). Технологии в образовании. «Человек», Москва, Россия, с.15-18.

Иванова, С. П. (2002). Учитель ХХІ века: ноопсихологический подход к анализу профессиональноличностной готовности к педагогической деятельности. ПГПИ им. С. М.Кирова, Псков, Россия.

Кларин, М. В. (1995). Инновации в мировой педагогике: обучение на основе исследования, игрь и дискуссии (Анализ зарубежного опыта). НПЦ «Эксперимент», Рига, Латвия.

Кларин, М. В. (1997). Инновачии в обучении: метафоры и модели: Анализ зарубежного опыта. Наука, Москва, Россия.

Корсакова, И. А. (2011). Философское обоснование применения интерактивных методов в образовании. Исторические, философские, политические и юридические науки, культурология и искусствоведение. Вопросы теории и практики. Тамбов, Россия, Грамота, № 4 (10): в 3-х ч. Ч. III. c. 65-69.

Краля, Н. А. (2005). Метод учебных проектов как средство активизации учебной деятельности учащихся: Учебно-методическое пособие, под ред. Ю.П.Дубенского. Изд-во ОмГУ, Омск, Россия.

Красильникова, В. А. (2006). Информационные и коммуникационные технологии в образовании: учебное пособие. ГОУ ОГУ, Оренбург, Россия. Лукас, Б. (2005). Обучение без торможения. Изд-во Эксмо, Москва, Россия.

Морев, И. А. (2004). Образовательные информачионные технологии. Часть 3. Дистанционное обучение. Учеб. пособие. Изд-во Дальневосточного университета, Владивосток, Россия.

Муратов, А. (2004). Информационные технологии в школах США. Москва, Россия, Учитель, № 5, c.84-87.

Новиков, А. М. (2000). Российское образование в новой эпохе. Парадоксы наследия, векторы развития. Эгвес, Москва, Россия.

Новиков, А. М. (2005). Развитие отечественного образования. Полемические размылиления. Издательство «Эгвес», Москва, Россия.

Новиков, А. М. (2006). Методология образования. Издание второе. Издательство «Эгвес», Москва, Россия.

Новиков, А. М. (2008). Постиндустриальное образование. Издательство «Эгвес», Москва, Россия.

Педагогические технологии: Учебное пособие для студентов педагогических специальностей (2004). Под общей ред. В.С.Кукушкина. Серия «Педагогическое образование». ИКЦ «МарТ», Москва, Россия + Издательский центр «МарТ», Ростов-на-Дону, Россия.

Поппер, Карл Р. (2002). Объективное знание. Эволющионный подход. Пер. с англ. Д.Г.Лахути. Отв. ред. В.Н.Садовский. Издательство «Эдиториал УРСС», Москва, Россия.

Рубинштейн, С. Л. (2003). Бытие и сознание. Человек и мир. Издательство «Питер», СанктПетербург, Россия.

Селевко, Г. К. (1998). Современные образовательные технологии: Учебное пособие. Издательство «Народное образование», Москва, Россия.

Селевко, Г. К. (2005). Педагогические технологии на основе информационно- коммуникационных средств. НИИ школьных технологий, Москва, Россия.

Селевко, Г. К. (2006а). Энциклопедия образовательных технологий: В 2 т. Т. 1. НИИ школьных технологий, Москва, Россия.

Селевко, Г. К. (2006b). Энияиклопедия образовательных технологий: В 2 т. Т. 2. НИИ школьных технологий, Москва, Россия. 


\author{
PROBLEMS \\ OF EDUCATION \\ IN THE $21^{\text {st }}$ CENTURY \\ Volume 51,2013 \\ 148 Сергеев, И. С. (2004). Основы педагогической деятельности: Учебное пособие. Издательство \\ «Питер». Санкт-Петербург, Россия. \\ Смирнова, Н. А. (2004). Развитие форм организации обучения в педагогической теории и практи- \\ ке. ПГПИ, Псков, Россия. \\ Современные образовательные технологии: учебное пособие (2011). / коллектив авторов; под ред. \\ Н.В.Бордовской. - 2-е изд.,стер. Издание «КНОРУС», Москва, Россия. \\ Учитель и ученик: возможность диалога и понимания (2002a). Том 1. Сост. Е.А.Генике, \\ Е.А.Трифонова, Под общ. ред. Л.И.Семиной. Издательство «Бонфи», Москва, Россия. \\ Учитель и ученик: возможность диалога и понимания (2002b). Том 2, Под общ. ред. Л.И.Семиной. \\ Издательство «Бонфи», Москва, Россия. \\ Федяинова, Н. В. (2004). Использование информационных технологий в учебном процессе началь- \\ ной школь. Учеб-метод. пособие. Омск. гос. ун-т, Омск, Россия. \\ Якиманская, И. С. (1995). Разработка технологии личностно-ориентированного обучения. Вопро- \\ сы психологии. Москва, Россия. Издательство «Педагогика», №2, с.31-42 \\ Ярошевский, М. Г. (1996). История психологии от Античности до середины ХХ века. Учебное \\ пособие. Издательство «Педагогика», Москва, Россия.
}

\title{
Summary \\ EDUCATIONAL TECHNOLOGY AS THE PSYCHOLOGICAL PROBLEM
}

\author{
Valentin Ageyev \\ University "Kainar", Almaty, Kazakhstan
}

The social contradiction between creative (generating) essence of the historical man and cognitive (adaptive) essence of the sociocultural man forms the basis of the research.

The scientific-psychological aspect of this problem represents the contradiction between the ability to act on the basis of the appropriated norms, samples and rules of the man as a product of traditional education and the modern society necessity of the man capable to make norm, samples and rules self-independently.

As means of the problem solution the new type of educational technologies based not on the mechanism of assignment but the mechanism of generation is offered.

The importance of research consists in the fact that the modern sociohistorical situation differs radically from the previous ones. The difference means, that social development is sharply accelerated now. The new educational systems are of great necessity at present such as systems turned not to the past (that is based on the assignment and reproduction of previous social experience) but to the future (that is based on generation of new social experience). Such reorientation is possible only as a result of education reorganisation from consuming past social experience to generating new social experience.

Creative method (method of creative experiment). In its basis there is a structure of creative dialogue, as the result of which the students in a problem situation generate new meanings (knowledge), which reveal new possibilities and present psychological means of new abilities designing.

Solution of a traditional education selectivity problem.

The technology of new possibilities designing represents the method of all the students without any exception self-development process organization.

The result of self-development is designing meanings (new possibilities) as means of new abilities generation.

Other results of experimental education are: ability to self-development; positive dynamics of educational motivation and self-determination of students; system knowledge designed by students, their "theoretical" (general) character; essential reduction of time of education as a result of qualitative change of its results. 
Валентин АГЕЕВ. Образовательная технология как психологическая проблема

\begin{tabular}{l|l} 
Key words: creative education, cognitive education, development, self-development. & $\begin{array}{l}\text { PROBLEMS } \\
\text { OF EDUCATION } \\
\text { IN THE 21 } 1^{\text {st }} \text { CENTURY } \\
\text { Volume 51, 2013 }\end{array}$ \\
\end{tabular}

Advised by Laima Railiene, University of Siauliai, Lithuania

Received: September 30, 2013

Accepted: January 26, 2013

Valentin Ageyev Dr., Professor, University "Kainar" , 4-27, Zhetysu-3 (box.25), Almaty, 050063, Kazakhstan.

E-mail: ageyev@mail.ru

Website: http://ageyev.kz 